\title{
Occupational exposure to pesticides: time to nip it in the bud?
}

\author{
$\mathrm{K}$ Mortimer, ${ }^{1,2}$ J Feary ${ }^{3,4}$
}

In Thorax, Negatu et al describe two cross-sectional studies exploring the effects of exposure to pesticides on lung health in commercial farming systems in Ethiopia. ${ }^{1}$ They found a markedly increased risk of chronic cough and shortness of breath and impaired ventilatory function in exposed versus unexposed groups. These studies are the largest of their kind conducted in Ethiopia or the wider sub-Saharan Africa. ${ }^{2}$

The finding that exposure to pesticides is associated with an increased risk of respiratory symptoms, airways disease and impaired ventilator function is, however, not new. Mamane et $a l^{2}$ published a review of the literature on occupational exposure to pesticides and lung health in 2015 that included 36 studies involving agricultural workers. The studies included in the review were broadly consistent in finding a positive association between occupational exposure to pesticides and a range of markers of lung health. ${ }^{2}$

In the UK, a high-income country, only $15 \%$ of workers have access to occupational health. It is therefore not a surprise that occupational health might be neglected in Ethiopia and other low/ middle-income countries under pressure from overwhelming social, economic and political challenges. ${ }^{3}$ Education about the risks of pesticide exposure is needed at all levels from farm workers to policy and decision makers. Previous studies have suggested low levels of knowledge and awareness of potential health hazards among farmers elsewhere in sub-Saharan Africa. ${ }^{4}$ Negatu et al focus on respiratory health, but pesticides can also be neurotoxic and are estimated to be responsible for 220000 deaths a year in low/middle-income countries alone due to intentional and accidental acute

\footnotetext{
${ }^{1}$ Department of Clinical Sciences, Liverpool School of Tropical Medicine, Liverpool, UK; ${ }^{2}$ Chest Centre, Aintree University Hospitals NHS Foundation Trust, Liverpool, UK; ${ }^{3}$ Department of Occupational Lung Disease, Royal Brompton and Harefield NHS Foundation Trust, London, UK; ${ }^{4}$ Department of Occupational and Environmental Medicine, National Heart and Lung Institute, Imperial College, London, UK

Correspondence to Dr K Mortimer, Liverpool School of Tropical Medicine, Pembroke Place L3 5QA,

Liverpool, UK; kevin.mortimer@|stmed.ac.uk
}

poisoning. ${ }^{6}$ So what can be done to reduce harm from pesticides in sub-Saharan Africa? Replacing the WHO class I and II pesticides with less toxic alternatives (or organic farming methods) would seem a logical first step. Pesticides with lower volatility and lower concentrations of active ingredients have been shown to significantly reduce occupational pesticide respiratory exposures. ${ }^{7}$ Workplace safety behaviours are also critical and include improved ventilation and use of respiratory protective equipment. In this study, respiratory health risks were seen within (on average) 4 years of exposure. Respiratory health surveillance would be a long-term aspiration and would help identify vulnerable workers early and potentially avoid development of chronic respiratory symptoms and disease.

The successful implementation of a new approach to occupational health in a country such as Ethiopia would rely on obtaining an understanding of a number of factors including farmers' knowledge, values and beliefs; the contribution of the agricultural sector to the overall economy; and the role and power of international and national agricultural-related business. ${ }^{8}$ It would also require agrochemical corporations to take greater responsibility, and controls on the import of banned chemicals. Occupational health should be part of a larger movement to ensure just and sustainable agricultural development. How to bring this about, and funding it, are just some of the challenges.

In this context, what messages can be drawn from Negatu et al' work? We propose there are four:

1. Those working in commercial farming settings in Ethiopia are among the world's poorest people, earning less than \$2 a day. They represent an underserved population that is vulnerable to exploitation-including being put at risk to harmful exposures, like pesticides-through their occupation. Without the work of investigators like Negatu et al, these people would lack a voice.

2. To many of us, mention of Ethiopia will bring to mind the 1983-1985 famine. That there are commercial farming systems in Ethiopia in light of this history is heartening. That cut flowers are being grown for export is perhaps less so, although as cash crops and lung health go we should perhaps be grateful that Ethiopia brings us coffee and flowers and not tobacco. WHO estimates that $40 \%$ of children under 5 in Ethiopia are stunted, 25\% are underweight and $9 \%$ are wasted. ${ }^{9}$

3. The time for studies which observe the harmful effects of occupational exposure to pesticides has now been and gone. As Negatu et al conclude, what is needed now is action in terms of occupational and environmental health interventions with a view to protecting pesticide workers. The place of clinical research in this arena should move boldly away from questions of 'Is it harmful?' or 'How harmful is it?' to 'What are the most effective and cost-effective ways to protect health?'

4. Pesticides exert their harmful effects on lung health following inhalation and as such represent a form of air pollution. The inhalation of polluted air kills around seven million people every year. ${ }^{10}$ The inhalation of tobacco smoke (also air pollution) kills another six million. ${ }^{11}$ Taken together, around 13 million people die every year from the inhalation of dirty air with most of these deaths being premature and in the world's poorest populations. It is in our interest and in those of future generations to identify and implement evidence-based solutions to air pollution in all its forms so that people everywhere have healthy clean air to breathe. Negatu et al's work speaks of a much broader agenda than the specific issue of the effects of pesticide exposure on lung health. It speaks of the 2030 Agenda for Sustainable Development and particularly of goals (1) no poverty, (2) zero hunger, (3) good health and well-being, (8) decent work and economic growth, (10) reduced inequalities, (12) responsible consumption and production, (13) climate action and (17) partnerships for the goals. ${ }^{12}$ In particular, it speaks of the need for healthy clean air for all to breathe.

Contributors KM and JF contributed equally to the authorship of this Editorial.

\section{Competing interests None declared.}

Provenance and peer review Commissioned; externally peer reviewed.

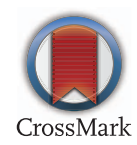




\section{Editorial}

To cite Mortimer K, Feary J. Thorax 2017;72:489-490.

Published Online First 11 January 2017

\section{CLLinked}

http://dx.doi.org/10.1136/thoraxjnl-2016-208924

Thorax 2017;72:489-490.

doi:10.1136/thoraxinl-2016-209686

\section{REFERENCES}

1 Negatu B, Kromhout $H$, Mekonnen $Y$, et al. Occupational pesticide exposure and respiratory health: a large-scale cross-sectional study in three commercial farming systems in Ethiopia. Thorax 2017;72:522-9.
2 Mamane A, Baldi I, Tessier JF, et al. Occupational exposure to pesticides and respiratory health. Eur Respir Rev 2015;24:306-91.

3 Ahasan MR, Partanen T. Occupational health and safety in the least developed countries-a simple case of neglect. J Epidemiol 200111:74-80.

4 Ngowi AV, Maeda DN, Partanen TJ. Knowledge, attitudes and practices (KAP) among agricultural extension workers concerning the reduction of the adverse impact of pesticides in agricultural areas in Tanzania. Med Lav 2002;93:338-46.

5 Ngowi AV, Maeda DN, Wesseling C, et al. Pesticide-handling practices in agriculture in Tanzania: observational data from 27 coffee and cotton farms. Int J Occup Environ Health 2001;7:326-32.

6 Bertolote JM, Fleischmann A, Eddleston M, et al. Deaths from pesticide poisoning: a global response Br J Psychiatry 2006;189:201-3.

7 Dowling KC, Seiber JN. Importance of respiratory exposure to pesticides among agricultural populations. Int J Toxicol 2002;21:371-81. Review.

8 Nuwayhid IA. Occupational health research in developing countries: a partner for social justice. Am J Public Health 2004;94:1916-21.

9 Nutrition in Ethiopia. Geneva: World Health Organization, 2014. http://www.afro.who.int/images/ galleries/2014/Ethiopia17062014/who\%20ethiopia\% 20-\%20nutrition\%20infographics.jpg?ua=1 (accessed 14 Nov 2016).

10 Health and sustainable development. Geneva: World Health Organization. http://www.who.int/ sustainable-development/news-events/breath-life/en/ (accessed 14 Nov 2016).

11 Tobacco: Fact sheet. Geneva: World Health Organization, 2016. http://www.who.int/ mediacentre/factsheets/fs339/en/ (accessed 14 Nov 2016).

12 Sustainable Development Goals. https:// sustainabledevelopment.un.org/topics/ sustainabledevelopmentgoals 